\title{
MalformaÇÃo No bebÊ E MATERNIDAde: ASPECTOS TEÓRICOS E CLÍNICOS ${ }^{I}$
}

\author{
Aline Grill Gomes* \\ Cesar Augusto Piccinini**
}

\section{Resumo}

Este trabalho apresenta uma revisão de estudos teóricos e clínicos acerca da maternidade no contexto de malformação do bebê. Inicialmente se discute o impacto do diagnóstico no psiquismo materno e na relação mãe-bebê e, num segundo momento, as intervenções psicológicas utilizadas nestas situações. Inquestionavelmente, o diagnóstico de malformação no bebê se revela como sendo uma experiência psíquica bastante complexa e difícil para a mãe, implicando em prejuízos psíquicos para ela e, consequentemente, para a relação mãe-bebê. Ademais, percebe-se que a representação mental que a mãe constrói acerca do bebê pode assumir um papel limitador ou potencializador do desenvolvimento psíquico do bebê. Os estudos destacam o quanto a representação psíquica materna merece ser examinada neste contexto de malformação, visando eventuais intervenções clínicas. A psicoterapia breve pais-bebê tem se mostrado uma técnica eficiente para acessar estas representações e redimensioná-las a favor de um crescimento psíquico mais saudável, tanto da mãe como do bebê. Assim, é importante que a malformação não seja tratada somente nos seus aspectos físicos e funcionais, mas também na sua dimensão psíquica.

Palavras-chave: malformação, maternidade, revisão teórica, psicoterapia breve.

* Psicóloga (Pontifícia Universidade do Rio Grande do Sul - PUCRS), Psicoterapeuta Psicanalítica (Instituto de Ensino e Pesquisa em Psicoterapia - IEPP) e Doutora em Psicologia do Desenvolvimento (Universidade Federal do Rio Grande do Sul - UFRGS).

** Doutor e Pós-doutor (University College London), Pesquisador do CNPq e Professor do Curso de Pós-Graduação em Psicologia do Desenvolvimento da Universidade Federal do Rio Grande do Sul (UFRGS). 


\section{Abstract}

BABY'S MALFORMATION AND MOTHERHOOD: THEORETICAL AND CLINICAL ASPECTS

This study presents a theoretical and clinical review concerning motherhood in the context of infant malformation. Initially, the impact of the diagnosis on the mother's psyche and on the mother-infant relationship is discussed, as well as psychological interventions geared toward them. Infant malformation diagnosis reveals itself as a quite complex and difficult psychic experience, implying psychic damages for the mother and, consequently, for the mother-infant relationship. Besides, the mother's mental representation concerning the baby can either facilitate or distort the infant's psychic development. Studies highlight the importance of examining maternal psychic representation in the context of malformation for eventual clinical interventions. Brief parent-infant psychotherapy has shown to be an efficient technique to access these representations in favor of a healthier psychic development for both mother and infant. Therefore, it is important that malformation is not only treated in its physical and functional aspects, but also in its psychic dimension.

Keywords: malformation, motherhood, theoretical review, brief parent-infant psychotherapy.

Embora na área médica (Nussbaum, Mcinnes \& Willard, 2002; Zugaib, 2004) seja feita uma distinção entre o termo "malformação" (que se refere a patologias estruturais) e "anomalias" e "síndromes" (que envolvem alterações cromossômicas), esta diferenciação nem sempre é explicitada na literatura psicológica, seja nacional ou internacional. É comum se encontrar estudos envolvendo bebês que não fazem esta diferenciação conceitual quanto às origens da malformação, destacando apenas as dinâmicas psíquicas decorrentes deste contexto. Embora os estudos revisados usem alternadamente diversos termos, decidimos, no presente trabalho, usar apenas o termo "malformação", que será utilizado para se referir às doenças físicas do bebê, sejam estas estruturais e/ou associadas a uma alteração cromossômica. O objetivo será o de examinar as repercussões psíquicas destas malformações para a maternidade.

É importante destacar que cada malformação, seja estrutural e/ou ligada a síndromes, apresenta inúmeras particularidades. Afora as diferentes etiologias, elas apresentam um grau diverso de visibilidade, com prognósticos e implicações clínicas variadas, exigindo cuidados especiais específicos. As mães e os pais recebem o diagnóstico em momentos diferentes do desenvolvimento do filho e de maneiras individuais, e isto tudo interage com suas próprias expectativas, conscientes e inconscientes, para com aquele filho. Frente a cada uma destas situações, é preciso considerar o potencial psíquico dos genitores para lidar com o diagnóstico, sem falar nas condições socioeconômicas da família e no conhecimento médico 
disponível para tratar determinada malformação. Todas estas dimensōes, entre muitas outras, interagem na determinação da complexidade de cada situação em particular e merecem ser levadas em conta ao se examinar e discutir a literatura sobre o impacto da malformação na maternidade.

Neste estudo, destacam-se, em particular, autores de orientação psicanalítica, sem, contudo, discriminar investigações oriundas de outras abordagens e que acrescentam concepções e dados importantes sobre a malformação, especialmente tendo em vista que se trata de um campo onde profissionais das mais diversas áreas têm dado suas contribuições. Além disto, é importante ter ciência de que a malformação é contextualizada e investigada sob diferentes enfoques, especialmente na sua dimensão emocional, foco do presente estudo, inclusive entre os autores de uma mesma abordagem, como, por exemplo, a psicanalítica. Assim, dada a extensão deste trabalho, eventuais diferenças conceituais muito específicas não serão destacadas, mas sugere-se que o leitor busque nos textos originais esclarecimentos sobre questôes que possam advir desta leitura.

\section{O DIAGNÓSTICO DE MALFORMAÇÃO E O PSIQUISMO MATERNO}

Se pensarmos a maternidade como uma crise vital e evolutiva, mesmo num contexto de normalidade, ocorrem ou precisam ocorrer diversos lutos (Santos, 2005). Entre estes, pode-se citar as perdas inerentes à condição de mãe, como, por exemplo, deixar o lugar de autonomia para ter agora um ser dependente de si ou, ainda, deixar a posição de filha para assumir a de mãe, sem falar nas inúmeras reformulaçōes psíquicas e relacionais acarretadas por essa nova identidade (Szejer \& Stewart, 1997). Assim, ainda que com muitos ganhos, há muitas perdas no que se refere à nova condição de mãe. Vale salientar que mesmo quando o bebê não apresenta qualquer problema de saúde o confronto do filho imaginário com o filho real já pode, por si só, gerar sentimentos de perda e aparecer associado a importantes focos conflitivos, os quais, se não elaborados, interferem na relação mãe-bebê (Lebovici, 1992; Schorn, 2002).

O nascimento de um filho com malformação é mais uma crise que se adiciona à própria maternidade e, nesta situação, Santos (2005) sugere que se tem uma crise tripla: vital, evolutiva e acidental. Durante a gestação e, por vezes, muito antes, o pai e a mãe constroem uma imagem do seu filho. Essa imagem é proveniente de suas próprias identificações, aspirações e frustrações (Schorn, 2002). Na situação de malformação, exacerba-se a distância entre o que se imaginou e desejou para o filho e o que a realidade mostra, e um grande número de projeções futuras 
acaba sendo abortado, tanto em relação a si mesmos como ao bebê. Com relação à identidade materna, Santos (2005) destaca que é possível que um filho com malformação remeta e reatualize o que é deficiente na história da mãe, aquilo que faltou, ao invés de representar uma chance de reparação deste faltante, como em uma situação normal. Assim, a questão da feminilidade, que é central na maternidade, através da condição de gestar, procriar e dar à luz um filho perfeito - o também conhecido filho imaginário do Édipo -, tende a não ser vivida com sucesso nesses casos (Mannoni, 1999). Escancaram-se, assim, as imperfeiçôes da mulher, provavelmente aquelas que ela desejava esconder com a maternidade, por ser, geralmente, uma condição vista em evidência.

Deste modo, todas as vivências de perdas que já são potencialmente difíceis em uma situação normal acabam maximizadas diante de um diagnóstico de malformação do filho, além de se criarem outras tantas experiências peculiares a esta situação que a tornam ainda mais dolorosa. E, como diz Sinason (1993), o nascimento de um filho é um evento público, que todos esperam e de que participam. Contudo, diante de uma intercorrência, seja qual for, tem-se uma imensa decepção que tende a gerar constrangimento, vergonha, culpa, medo e raiva. Dias (2006) entende que toda essa gama de sentimentos leva a um estado de desequilíbrio nos pais, na medida em que causa fratura no ideal que a criança representaria e atinge toda a rede de significações dos agentes parentais. A angústia, o desamparo e a incerteza tomam conta dessa relação. A autora chama atenção para o fato de que a lesão que se instaura vai muito além da condição orgânica. Como diz Schorn (2002), é uma marca real e eterna, que da mente nunca vai desaparecer. Assim, os pais, frente a uma situação de malformação, precisam se adaptar a esta nova realidade de dificuldades e de dores. Isto é, mesmo que o filho melhore e supere as restrições decorrentes da malformação, ainda que tudo isto se torne amenizado na vida deles, o registro das experiências passadas por conta deste contexto é indelével.

Essa adaptação segue um ritmo particular para cada caso, porém é possível falar de algumas etapas comuns àqueles que passam por um processo de luto. As reaçôes parentais frente a notícias de malformação nos bebês foram descritas em um estudo clássico por Drotar, Baskiewicz, Irvin, Kennel e Klaus (1975) que, a partir de suas observaçôes, sugeriram fases de organização dessas reações, a saber: choque, negação, tristeza e cólera, equilíbrio e reorganização. A individualidade de cada pai, de cada mãe e de cada casal vai influenciar não somente a forma de viver cada fase (Irvin, Kennel \& Klaus, 1993), mas também no tempo despendido em cada uma delas e na capacidade de chegar ou não à fase de reorganização. $\mathrm{Na}$ verdade, a intensidade das repercussōes emocionais é dificilmente avaliada, mas existem fatores fundamentais na qualidade de elaboração do luto, tais como: o 
momento em que é dada a notícia, a gravidade da malformação, a paridade do casal (Kroeff, Maia \& Lima, 2000), além do próprio diagnóstico, prognóstico, tipo de cuidado necessário ao filho (Goldberg, Morris, Simmons, Fowler \& Levison, 1990) e, por fim, os recursos externos (apoio) e internos (estrutura psíquica) disponíveis (Pelchat, Bisson, Ricard, Perreault \& Bouchard, 1999).

De qualquer forma, o recebimento da notícia de malformação em um filho, seja antes ou logo após o nascimento, é sempre uma vivência de crise intensa e equilíbrio emocional próximo à disrupção (Tradup, 1990). O choque inicial, que se desencadeia pela consciência de que a criança não corresponde à imagem ideal, poderia, inclusive, deixar os pais estupidificados diante do traumatismo que uma situação desta representa (Debray, 1988). Com isso, ocorreria uma profunda vivência de perda e luto, instalando-se na mãe uma "ferida narcísica". Ela tem com isso sua autoestima diretamente afetada, uma vez que seu filho é considerado como sendo sua extensão (Ramona-Thieme, 1995; Santos, 2005; Schorn, 2002). Assim, os pais precisam admitir uma perda narcísica importante, a vulnerabilidade da sua autoestima, pois não poderão duplicar-se em um belo e saudável bebê (Brazelton \& Cramer, 1992). Trolt (1983) salientou ainda que o insulto ao narcisismo é tão intenso que, para preservar pelo menos um pouco da autoestima, os casais chegam a se afastar, podendo, assim, projetar um no outro a culpa pelo "erro".

Deste modo, o diagnóstico acarretaria uma espécie de desintegração de sentimentos, isto é, as expectativas e afetos que estavam sendo dirigidos ao bebê sofreriam uma quebra, dando lugar à culpa, raiva, sentimentos de impotência, frustração e resignação (Kroeff et al., 2000). Com isso, os autores acreditam que se desencadeariam nas mães dois mecanismos principais. $\mathrm{O}$ primeiro é a perda da autoimagem, pois o desejo de ver refletida no filho uma imagem sua - robusta, saudável e perfeita - se rompe diante da realidade que não é assim, o que acaba por desorganizar sua própria imagem. O segundo mecanismo é a perda da autoestima, que ocorreria pela crença na própria incapacidade de produzir uma prole normal.

Nesse contexto, a identificação maciça da mãe com o seu filho é que acarretaria os prejuízos no narcisismo e na autoestima, fazendo com que a mãe se sinta "defeituosa" (Shorn, 2002). Isso a faz reduzir, inclusive, suas necessidades pessoais. É como se não precisasse mais se preocupar tanto consigo e com seu bem-estar, já que seria imperfeita e não mereceria tanta dedicação. Nos casos em que o filho foi especialmente desejado para preencher um espaço narcísico da mãe, esse impacto seria ainda maior e se constituiria num trauma importante. Estas mães, em geral, conforme Chess e Hossibi (1982) apontam, já resguardam em si um sentimento latente de inadequação, ou melhor, um prejuízo narcísico que se reflete também 
na maternidade, e a ocorrência de uma malformação no filho só traria à tona tal realidade psíquica.

Assim sendo, a maternidade e o papel materno são profundamente afetados pelas características do bebê, sua aparência e suas respostas (Gordeuk, 1976). A própria possibilidade de acesso às capacidades maternas estaria intimamente associada à identificação do bebê como um ser separado e real. Só que este processo de identificação é lento e complicado. Segundo Rubin (1975), inicialmente é preciso ocorrer uma associação mãe-bebê, depois uma diferenciação e, por último, a comprovação de ver o bebê inteiro e intacto. Nos casos de malformação no filho, esta última premissa fica prejudicada. A mãe, mesmo que tenha conseguido se associar e se diferenciar, o que também provavelmente ocorre com dificuldades, não consegue enxergar o bebê intacto, o que pode levá-la a não concebê-lo separado dela, real e, portanto, com potencial de crescimento. Como a maternidade e o papel materno estão atrelados a esta necessidade, quando o filho tem algum problema o processo e o exercício materno tendem a sofrer o que Rubin (1975) chama de "ruptura". Para restabelecer a continuidade, a mãe precisa, primeiro, passar pelo luto da perda do bebê representado e idealizado.

Talvez pela gravidade, intensidade e extensão de todas estas disrupções psíquicas e familiares é que algumas mães nunca superam completamente o fato de o filho ter nascido com uma malformação. No estudo de Trolt (1983), uma mãe referiu que a cada ausência de resposta evolutiva da filha a vivência da dor de seu nascimento, com todas as dificuldades impostas, se remontava. Assim, o bebê perfeito fantasiado por vezes fica como um fantasma na mente da mãe e serve para incrementar seu sofrimento cada vez que é comparado com o bebê real. Porém o autor sublinhou a normalidade destes sentimentos dada a situação, afirmando que a perda não termina quando há uma aceitação do bebê real. Essa recorrência da perda não representa, então, a não-aceitação e sim o luto pelo bebê que "morreu". Drotar et al. (1975), ao se referirem à penúltima fase do processo de luto, a de adaptação, enfatizaram que mesmo que os pais consigam atingir esse estado adaptativo frente à malformação do filho isto nunca seria completo. Mesmo passados anos do impacto do diagnóstico, haveria momentos de revivência do sofrimento, com importantes repercussões para a relação mãe-bebê.

\section{MALFORMAÇÃo NO BEBÊ E A RELAÇÃo MÃE-BEBÊ}

Como visto acima, a descoberta do diagnóstico de malformação e a vivência de luto marcam a relação dos pais com a criança por toda a vida (Quayle, 1997) 
devido à intensidade das dificuldades enfrentadas. Podem surgir sentimentos ambivalentes em relação ao filho, projeções massivas sobre ele, além de outras reações perturbadas - uma verdadeira "tempestade psíquica" que muitas vezes precisa de cuidados profissionais para não causar efeitos nefastos na relação paisbebê (Maury, 1999).

Essa dificuldade na relação já foi descrita inicialmente por Freud ([1926] 1969), que postulou que, diante do sofrimento, o movimento psíquico natural é desinvestir a libido do outro e do externo e reinvestir em si mesmo. Por esta razão, Bertoldi (2002) acredita que, pelo menos nos momentos iniciais, é muito difícil para os pais lidarem com um filho com malformação e investirem em seu desenvolvimento. Eles estão sofrendo muito, passando por um luto, e ainda lhes é exigido cuidar do filho, se relacionar com ele e acreditar na sua evolução - objetivo esse que, apesar de aparentemente natural, passa a ser quase impossível de ser atingido, se levadas em conta as necessidades e dificuldades psíquicas advindas destas situações.

Por essa razão, podemos elencar uma série de dificuldades, de natureza variada, comumente enfrentadas nesses momentos iniciais após o diagnóstico de malformação. Essas dificuldades geram também diferentes reações das mães em relação ao filho. Uma delas é o retraimento dos afetos como proteção pela dor e ameaça do próprio contexto que, por vezes, já começa desde a gestação (Raphael-Leff, 1997; Roelofsen, Kamerbeek \& Tymstra, 1993). Por exemplo, em uma revisão teórica realizada por Crow (1996) acerca de bebês com malformaçōes cardíacas, foi enfatizado que os pais tendiam a relutar em se ligar ao bebê, pois ele poderia não sobreviver.

Ou seja, são muitas incertezas inerentes a esta situação. Como a continuidade psíquica de um bebê só pode ser melhor garantida se apoiada no desejo do "Outro", ou seja, na medida em que o bebê significa vida e complemento para ela, então ele fica inscrito na mente da mãe e, portanto, passa a existir com mais força. Nos casos de malformação e maior incerteza ainda sobre o futuro do filho do que comumente acontece em qualquer gestação, essa noção e o desejo de continuidade ficam frágeis e o investimento libidinal fica reduzido (Dias, 2006). Debray (1988) fala de uma espécie de reação de freio na circulação de afetos das mães em relação a seus filhos com malformação, como se houvesse constantemente uma necessidade de não investir, na dúvida de que eles vão progredir com boa saúde. Assim, parece que tanto antes como depois do nascimento os sentimentos maternos, dependendo da situação, podem ficar, por defesa, resguardados até a certeza da sobrevida do bebê e das suas condiçôes para se desenvolver.

Como já foi enfatizado anteriormente, a idealização e a libidinização do filho precisam ocorrer para uma melhor constituição do psiquismo. Contudo, quando 
os pais se deparam com um diagnóstico de malformação, esse processo tende a ficar prejudicado (Brazelton \& Cramer, 1992). Caso não seja depois recuperado este investimento positivo dos pais no filho, podem ocorrer diversas saídas conflituosas deste processo. Para Brazelton e Cramer (1992), podem-se instaurar nos pais desde quadros de ansiedade e depressão até uso de projeçōes patológicas, que tornam a criança um bode expiatório e receptor de todas as falhas dos pais e/ou da família. Por outro lado, é possível também que ocorra uma intensa devoção e dedicação dos pais como reação à sua culpa, o que pode se traduzir em uma atitude de superproteção, sufocando, com isso, o desenvolvimento da criança (Brazelton \& Cramer, 1992; Prada, Valle \& Pimentel, 2000). Ao se tornar um "coitado", através de uma atitude evidente de falso protecionismo, o bebê passa a ocupar um espaço especial e livre de agressões, as quais estão inquestionavelmente presentes no inconsciente dos pais, que acaba por livrá-los dessa aterrorizante culpa que normalmente os acompanha nestas situaçōes (Schorn, 2002). Sinason (1993) compartilha desta ideia quando refere que a rejeição inicial por parte dos pais pode converter-se em um estado de superproteção em relação ao filho, o qual também pode prejudicar o seu desenvolvimento psíquico. Isto fica particularmente acentuado quando o bebê passa a ser visto como muito vulnerável e incapaz (Waisbren, 1980).

O filho pode não ser visto, então, como capaz de realizações e de vida e, portanto, comumente, é salvaguardado de sofrimentos; uma superproteção que leva a um "fúnebre enclausuramento" (Jerusalinsky, 2002). Isso sim remete à morte, uma segunda morte que, conforme este autor, é a de um ser que, mesmo vivo, é dito, visto e vive como morto. De acordo com Jerusalinsky (2002), é preciso ajudar os pais a reconhecer que o pior que pode acontecer na vida de alguém é que nada lhes aconteça. Santos (2005) acrescenta que é importante a ideia de um filho com uma malformação e não a de um filho malformado, mantendo, assim, uma noção subjetiva e singular do sujeito. Deste modo, nosso papel, como profissionais da saúde, é auxiliar os pais a não se centrarem simplesmente nas limitações e impossibilidades de determinada malformação e sim estar sempre atentos às possibilidades e restriçôes particulares desse bebê.

É claro que a presença da malformação tende a ser algo inexorável, está ali e precisa ser olhada, cuidada, tratada. Inquestionavelmente também o bebê irá se deparar com limitações. Porém o quantum disso é que está em discussão. Sabemos que uma mesma patologia apresenta diferentes níveis de seriedade, como já assinalamos no início deste artigo, e, obviamente, pode assumir inúmeras representaçóes psíquicas inconscientes, dependendo de quem a porta ou olha (Jerusalinsky, 2001). Estas poderão, então, ser mais ou menos propiciadoras ou limitantes para 
o bebê se desenvolver e se constituir como sujeito. Se a objetividade acompanha o diagnóstico médico, não se pode dizer o mesmo em relação aos aspectos psíquicos; estes se constituem em uma parte fundamental do grau de superação da situação. Jerusalinsky (2001) defende, inclusive, que os efeitos imaginários das patologias resguardam mais o seu prognóstico do que o quadro clínico em si. Embora isto possa ser visto como uma afirmação exagerada - especialmente em situações de extrema gravidade de determinado quadro clínico -, o autor aponta dois mecanismos que se interpõem no estabelecimento do laço mãe-bebê em situaçôes de malformação: o mecanismo das profecias autorrealizáveis e o da antecipação de insuficiência no bebê. O primeiro envolve uma crença de fracasso, mesmo quando existe potencial para o sucesso. Assim, as açóes são todas baseadas na expectativa e na certeza do negativo, levando, então, a se confirmar esse fim. A "incapacidade" do bebê acaba sendo maior do que a patologia orgânica que a determina, em função das expectativas do imaginário parental. O segundo mecanismo, o de antecipação das insuficiências no bebê, tem a ver com uma "passivização psíquica", que envolveria uma antecipação da incapacidade nas demandas que poderiam lhe ser impostas. Assim, a família o faz passivo às técnicas profissionais para ele buscadas, tirando-lhe a chance e o lugar de ativo no seu progresso. Deste modo, tem-se claro que pode haver uma indiscriminação entre as limitações físicas do bebê e o que ele pode ser psiquicamente nas representações dos pais.

Alguns estudos (e.g. Chess \& Hossibi, 1982) parecem apoiar estas ideias, ao mostrar uma alta associação entre deficiência física e doenças psiquiátricas na criança, enfatizando o que chamaram de "efeito cruzado de deficiências em áreas não afetadas". Isto é, primeiro tem-se o problema da criança com suas limitações específicas e, depois, a maneira com que os pais vão lidar com as mesmas. Caso os pais enxerguem e tratem o problema de forma patológica, por exemplo, exacerbando suas implicações e restringindo as potencialidades da criança através de uma atitude de superproteção, ter-se-á um incremento das próprias limitações, o que nem sempre decorre da patologia em si e sim do tipo de relação estabelecida entre os pais e o filho. A atitude de superproteção também pode decorrer do medo de que aconteçam eventos ainda mais traumáticos com o bebê (Sinason, 1993), já que ele tende a ser visto, pela mãe, como muito frágil e doente, sem condições de se defender. É como se a vulnerabilidade dele estivesse sempre representando uma porta aberta para mais tragédias, as quais poderiam, fantasiosamente, ser evitadas pela sua postura de proteção excessiva. Podemos pensar que essa atitude não deixa de significar uma tentativa de se livrar também da impotência, sentimento tão inerente a tais situaçôes, e servir, inclusive, como um cuidado maior e zeloso para com a criança. Neste contexto, a culpa e, particularmente, a superproteção 
da mãe podem representar, dependendo da intensidade, uma proteção adaptativa, em certa medida necessária para o desenvolvimento do filho.

Além da superproteção e da ideia de incapacidade, ou da proteção adaptativa e zelosa, podemos identificar também uma postura mais rechaçante da mãe em relação ao bebê (Santos, 2005; Schorn, 2002). Por ser um encontro que a mãe não está esperando, e bem distante do imaginado, a mãe pode ter dificuldades, em um primeiro momento, de reconhecer o bebê como seu filho. Ela se sente frente a um estranho, um pedaço de si mesma totalmente desconhecido. Isso provoca, segundo Schorn (2002), falhas no processo de narcisização do bebê, na medida em que o seu investimento libidinal fica falho. Ela não consegue, mesmo que inconscientemente, ver no bebê um objeto de identificação, reconhecê-lo como uma extensão de si. Assim, o bebê também pode se deparar não com um olhar acolhedor que reflete satisfação e admiração, mas, sim, com um olhar deprimido e angustiado. A identidade do bebê recebe essas implicações, podendo este passar a se enxergar com desvalia por não sentir sua imagem capaz de encantar sua mãe.

Neste contexto, a dificuldade de identificação passa por uma questão de espelhamento, o qual também tem relação com o corpo (Schorn, 2002). Antes de se encontrar com seu filho, a mãe se encontra com um corpo, a partir do qual libidiniza e constitui psiquicamente aquele sujeito. A mãe tende a se enxergar no bebê e este na mãe. Há uma interação contínua e permanente e o bebê é ativo nela. O feedback de um para o outro se retroalimenta, solidificando o vínculo de apego. Nesse sentido, Schorn (2002) cita Ajuriaguerra na sua ideia de que o bebê constrói a mãe e a mãe, por sua vez, também constrói o bebê. Solis-Ponton (2004) acrescenta que o filho faz os pais, os parentaliza ao mesmo tempo que se constitui como ser. Se a mãe sente que satisfaz seu filho, isso gratifica seu narcisismo e lhe confere a identidade materna. É um entorno dinâmico com interaçóes complexas que, se harmonioso, permite espaço para essa construção mútua e singular que nunca se repetirá da mesma maneira com outra dupla. Essa relação leva à constituição psíquica do bebê.

É através do contato do seu corpo com o corpo da mãe que o bebê adquire sua capacidade perceptiva (Anzieu, 1989). Surge o que este autor chama de "Eu-pele", uma noção integrada de si a partir da identificação com um objeto primário seguro que o contém. Para que a mãe se ofereça como este objeto, ela precisa reconhecer o filho como seu e estar disposta a emprestar seu corpo, pele e psiquismo para sua constituição. Essa etapa inicial, conforme Solis-Ponton (2004), se desenvolve em nível corporal, mais precisamente entre o corpo físico da mãe e do bebê. Esse é o cenário da interação, onde se constitui, de acordo com a autora, o plano primário da inscrição psíquica, cujo mecanismo central é a identificação. Portanto, o papel 
de espelho é fundamental para que o bebê possa se formar e se reconhecer no olhar da mãe. Estando o corpo com algum problema, esse processo fica afetado (Schorn, 2002). O bebê não é o que se esperava e, portanto, se torna impensável, irrepresentável em um primeiro momento. Se pensarmos que a mãe se enxerga no bebê e vice-versa e que esse espelhamento é essencial no desenvolvimento, pode-se supor, segundo a autora, que no contexto de malformação há grandes possibilidades de desencontros. Solis-Ponton (2004) nos fala que esses desencontros têm a ver com o tipo de objeto que o bebê pode se tornar aos olhos da mãe. Assim, se o bebê for sentido como um objeto de trauma, o processo de identificação fica prejudicado e o "espelho", rachado. Todo esse impacto da malformação no psiquismo materno pode, por consequência, interferir no psiquismo do bebê (Malucelli, 2002). Além disto, o tempo que essa ferida corporal demora para cicatrizar - o que está associado às consultas médicas, procedimentos cirúrgicos e cuidados gerais - pode se estender por anos e pode equivaler ao tempo que o psiquismo também precisa para se reerguer, tendo em vista a dimensão do trauma. Reiterando estas ideias, Malucelli citou uma passagem de Aulagnier (2002): "Alguns segundos serão suficientes para fraturar seu corpo. No melhor dos casos, meses são necessários para que os pedaços se ressoldem e muitos outros meses para achar mecanismos que compensem a deficiência funcional que dali pode resultar" (Aulagnier, 2002: 145).

$\mathrm{Na}$ verdade, diante da intensidade e da extensão das dificuldades, mesmo passado muito tempo do diagnóstico, corre-se o risco de a ferida narcísica instalada nos pais diante da malformação no bebê não "cicatrizar". Nestes casos, os pais podem se ver intensamente responsabilizados, com riscos de aparecerem, assim, a depressão, os conflitos conjugais, além das culpas projetadas em familiares e na equipe médica. São comuns atitudes de rejeição e raiva em relação à própria criança, ou em relação a ter uma criança com menos potenciais. Inconscientemente, não "cabe" mais ter uma criança que evolua (Brazelton \& Cramer, 1992; Waisbren, 1980). O apego, nesses casos, não se desenvolveria (Brazelton \& Cramer, 1992) ou ficaria difícil de ser estabelecido (Maury, 1999).

Contudo, os achados relatados na literatura nem sempre apontam nesta direção. Por exemplo, o estudo de Speltz, Endriga, Fisher e Mason (1997) sobre o estabelecimento do apego em situações de malformação comparou a interação de dois grupos de mães norte-americanas e seus bebês, aos três meses de vida, sendo 56 deles com fissura labial e/ou palatal e 56 sem qualquer diagnóstico de malformação. Apesar de suas expectativas iniciais envolverem a ideia de uma menor responsividade nas díades mães-bebês com fissura, elas não foram confirmadas nos resultados e não foram encontradas diferenças no apego mãe-bebê em bebês com ou sem o diagnóstico. $\mathrm{O}$ interessante é que a explicação dos autores, baseada em 
dados de entrevistas, foi de que estes achados estavam enviesados pelas atitudes de superproteção das mães, que, por culpa, assumiram uma conduta reativa. Para além destas explicações dos autores, é plausível se pensar que, em alguns casos, podem ter predominado aspectos saudáveis na relação mãe-bebê, apesar da malformação.

No entanto, outros autores também reforçam uma ideia mais patologizante das relaçôes que envolvem malformação no bebê (Colares \& Richman, 2002). Revisando extensamente a literatura sobre fatores psicológicos relacionados à fissura labiopalatal, os autores salientaram que a relação mãe-bebê tende a se tornar bastante complicada. O contato visual e o toque, elementos essenciais para uma boa qualidade de relação, tendem a ser menos frequentes nestas duplas, uma vez que as mães de bebês com esta malformação apresentam-se mais inibidas para o contato físico com eles. Os autores ainda apontaram que quanto mais atrativa fisicamente é uma criança, mais chance ela tem de receber atenção. Stern (1999) acrescenta que as mães sentem medo de machucar um ser tão delicado e, por isso, podem se retrair na interação com ele.

No tocante às malformações cardíacas, especificamente, alguns estudos apontaram que, por se tratar, em geral, de quadros clínicos bastante ameaçadores do ponto de vista de gravidade, a interação tende a ficar consideravelmente prejudicada. Por exemplo, Svavarsdottir e McCubbin (1996) observaram 71 díades de mães e bebês de até um ano de idade que apresentavam cardiopatia congênita. Os resultados mostraram que as mães ficavam muito receosas em interagir com seus bebês por medo de lhes causar qualquer dano que levasse a uma crise, o que gerava uma interação carregada de estresse. A pesquisa mostrou que a interação mais demorada era a alimentação, justamente pelo temor materno de engasgar o bebê e ele ter uma crise cianótica. Os momentos de interações mais afetivas envolvendo o brincar, vocalizar foram pouco frequentes entre as duplas observadas. Carey, Nicholson e Fox (2002) corroboraram estes achados, ao afirmar que perceberam que as mães de bebês com cardiopatia se mostraram demasiadamente vigilantes durante a interação, também pelo medo de causar algum mal ao bebê.

$\mathrm{Na}$ verdade, a ambivalência de sentimentos e reações é o que parece mais caracterizar as relações com um filho com malformação, e isto tem sido amplamente descrito na literatura (Johonsson \& Ringsberg, 2004; Trolt, 1983; Waisbren, 1980). Esses sentimentos estão bastante presentes desde o primeiro encontro dos pais com seus filhos (Johonsson \& Ringsberg, 2004), mas também se presentificam ao longo do desenvolvimento da criança (Trolt, 1983; Waisbren, 1980). Especificamente, vale ressaltar a pesquisa de Trolt (1983), que acompanhou durante sete anos famílias de bebês com malformação, bebês que tinham inicialmente entre 0 e 30 meses de vida. $\mathrm{O}$ autor refere que os pais chegaram a relatar simultaneamente sentimentos 
de amor e ódio, orgulho e vergonha, desejo de morte e de sobrevivência, desejo de ajudar e de ignorar, desejo de estar com outros pais e desejo de evitá-los. A vivência da ambivalência costumava ser muito dolorida em termos emocionais, pois os pais não entendiam o que estava acontecendo com eles, além de experienciarem muita culpa quando percebiam os sentimentos negativos.

Nesta mesma direção, Schorn (2002) também salientou a ambivalência intensa presente no contexto de malformação. Ela diz que, em geral, ocorre uma morte imediata da mãe e do filho idealizados. E, se não morrem completamente logo, incita-se o suicídio. Ou seja, por vezes são criados obstáculos que nem mesmo existem, mas a morte parece ser buscada. É como se a mãe se convencesse de que não há soluções ou de que aquele terror não vai findar, tamanho o desespero, desamparo e impotência diante da longa estrada que a espera, de tratamentos, consultas, cirurgias e, o pior, de medos, incertezas e ameaças de morte. Coexistem, então, o desejo de cuidar e proteger com reaçōes de dor e ódio por tudo que é preciso passar. Segundo Dias (2006), esse desejo de fim e de morte é o que aumenta o intervalo entre o nascimento concreto da criança e a emergência do sujeito, isto é, o "desabrochar" da criança que, confinada à dúvida da sua sobrevivência, fica sem muito espaço para viver e constituir sua identidade.

Enquanto a mãe não se apropriar e reconhecer o filho como seu, este pode demorar a ser visto como sujeito do desejo. Isto pode levá-lo à dificuldade de se apropriar imaginariamente de um corpo, que significa um palco para o desenvolvimento de sua autonomia e suas capacidades (Birchal, 2006; Jerusalinsky, 2002). Só que, para tanto, por vezes precisamos suportar o desejo real de morte dos pais em relação a este filho ao invés de dedicarmo-nos a observar, instigar e aceitar somente os investimentos imperativos de vida. A vida a qualquer preço não é o que sempre aparece nessas situações. Como salientou Freud ([1913] 1969): "O mais terno e mais íntimo dos nossos vínculos de amor, com exceção de pouquíssimas situações, leva aderida uma partícula de hostilidade que pode incitar o desejo inconsciente de morte" (Freud, [1913] 1969: 38). Aceitar esse desejo de mães e pais, acolhendo-os e ajudando-os na sua compreensão, é o único caminho, conforme Jerusalinsky (2002), para tirar o bebê da condição de segunda morte, vivo-morto, possibilitando que a vida do bebê vá além do orgânico e passe a ser simbólica, sustentada nas bases de desejo e demanda.

Estas ideias recebem apoio de diversos estudos empíricos. Por exemplo, o estudo de Farel, Freeman, Keenan e Huber (1991) examinou a interação de 74 díades mãe-bebê norte-americanas, metade das quais em situações de normalidade e as demais em situação de alto risco para o bebê, incluindo malformaçôes. Os resultados revelaram que as díades de alto risco apresentavam um padrão de 
interação significativamente prejudicado, com menos capacidade de expressar sensaçōes de prazer e de desconforto, mostrando-se afetivamente mais rígidas. $\mathrm{O}$ estudo de Gardner, Freeman, Black e Angelini (1996) observou a interação de mães e seus bebês com e sem diagnóstico de malformação cardíaca. A interação foi filmada dois dias após o parto e novamente depois de seis meses. As mães do grupo clínico demonstraram menos afetos positivos e engajamento na interação, além de se apresentarem mais instáveis e psicologicamente estressadas nos dois momentos observados, demonstrando ainda pouca habilidade para se adaptar aos bebês, mesmo após seis meses de convívio. Já De Maso et al. (1991), num estudo com 99 mães norte-americanas e seus filhos com malformações cardíacas, investigaram o quanto a própria relação mãe-bebê e a severidade da malformação poderiam influenciar o ajuste emocional futuro da criança. Os resultados revelaram que a qualidade da relação apresentou maior peso preditor do ajuste emocional da criança do que a severidade da malformação. Em um estudo anterior dos autores do presente artigo, foram acompanhadas três mães e seus bebês com malformação (i.e. mielomeningocele e gastrosquise) durante o final da gestação, o parto e o pós-parto. Os resultados revelaram reaçōes de bastante sofrimento, com a presença de mecanismos de negação em relação ao problema apresentado pelo bebê, o que aparecia quando as mães destacavam com ênfase o potencial de saúde justamente dos membros e partes do corpo do bebê atingidas pela malformação. Ademais, notou-se uma postura de superproteção evidente para com o bebê, chegando, em um dos casos, a uma relação simbiotizada e indiscriminada. Neste caso em particular, isso pareceu ter acontecido devido, especialmente, ao abandono do pai que, em virtude do recebimento do diagnóstico, nunca mais retornou ao convívio familiar. A mãe colocou no bebê a responsabilidade por cuidá-la e acompanhá-la, para sempre.

Embora as repercussões psíquicas da malformação para a própria criança não sejam o foco do presente estudo, é importante destacar que este tema também merece novas investigaçóes, visto a sua relevância e por estar intimamente ligada à relação mãe-criança. À guisa de exemplo, destaca-se o estudo de Schorn (2002), que salientou que, nos casos de malformação em que múltiplas cirurgias são realizadas nas etapas iniciais do desenvolvimento, quando a discriminação "eu/nãoeu" não está ainda bem estabelecida para o bebê, isto pode ter importantes efeitos na formação da identidade. Soma-se a isto o fato de que a criança tem seu corpo como palco, que tem grande participação na constituição do self. Nesse sentido, sabe-se que bebês e crianças com malformação têm ansiedades primitivas mais intensamente persecutórias do que os demais. Assim, é importante que a mãe apresente uma capacidade de rêverie (Bion, [1976] 1992), o que permite que ela capte 
intuitivamente o que se passa com o filho, que deseje compreender e responder às suas necessidades com sensibilidade. Conforme Agazi, Arenaza, Carranza, Malik, Shorn (2002), uma aceitação carinhosa ou uma atitude rechaçante funciona como fator determinante para como este bebê vai se enxergar.

Reiterando o que já foi destacado acima, em casos de ocorrência de uma malformação no bebê, a relação mãe-bebê assume um papel limitador ou potencializador do desenvolvimento psíquico dele. A partir do exposto, fica evidente que as representações da própria mãe sobre a maternidade e sobre o bebê têm um papel essencial nesse prognóstico. Utilizando as formulações de Stern (1997) sobre o tornar-se mãe e o desenvolvimento infantil, chegamos à ideia de que o mundo das representações de mães e pais possui um papel determinante na natureza do relacionamento pais-bebê, tão ou mais importante do que o mundo externo real. Esse mundo representacional refere-se a como mães e pais experienciam e interpretam subjetivamente os eventos objetivamente disponíveis na interação com o bebê, englobando os seus comportamentos e também os comportamentos do bebê. Por isso, dele fazem parte não somente as experiências dos genitores resultantes da interação atual com o bebê, mas também suas fantasias, medos, sonhos, lembranças da própria infância, modelos de pais e expectativas para o futuro do bebê.

Stern (1997) não se dedicou especificamente à questão da malformação, embora tenha registrado algumas ideias sobre o tema que nos fazem supor como podem ficar as representações maternas nesta situação. Como o autor destaca que as representações pressupõem uma experiência subjetiva de estar com o bebê, o que pode ser mental ou real, isso remete à possibilidade de imaginar, significar e esperar o bebê. Diante de uma malformação, Stern (1997) salienta que mães e pais não podem planejar e elaborar um curso de desenvolvimento para seu filho; eles são impedidos, por uma realidade médica, de ter uma ideia mais concreta sobre o seu futuro. Mais tarde, Stern (1999) acrescentou que, nesse contexto, a mãe está privada de ampla parte do processo imaginativo, e isso é um dos maiores choques possíveis na maternidade.

$\mathrm{Na}$ verdade, o desenvolvimento de todos os bebês, por mais saudável que seja, é incerto. Mas, nos casos de malformação, ou mesmo quando de acentuada prematuridade, Stern (1997) diz que existe uma impossibilidade de construir uma estrutura representacional futura, o que coloca a mãe e o pai num "vácuo representacional”. Diz ele: "Quando nós não podemos imaginar o futuro, não podemos avaliar o presente. Um dos pilares de todo o empreendimento da representação foi retirado" (Stern, 1997: 42). Conforme o autor, caso as mães e os pais não sejam ajudados a olhar para este vácuo representacional, corre-se sério risco da ocorrência de um fracasso na ontogênese da representação destes pais sobre a 
criança presente e futura, além de um correspondente fracasso na representação da criança sobre si mesma.

Além disso, podemos pensar que os temas da constelação da maternidade também propostos por Stern (1997) podem ficar bastante alterados na vivência de um filho com malformação, como destacado por Gomes (2007). O primeiro deles, que trata do tema vida e crescimento, isto é, da tarefa de manter o filho vivo e seguindo um sadio desenvolvimento, é completamente abalado pela malformação, em que o futuro é completamente incerto. $\mathrm{O}$ segundo tema, o do relacionar-se primário, no qual se trata de a mãe reconhecer o bebê como seu e se entregar às suas necessidades, tende a ser uma tarefa difícil de ser cumprida quando o bebê tem uma malformação. Como já foi visto, as mães tardam em reconhecer este filho como seu na medida em que não o enxergam como gostariam. $\mathrm{O}$ investimento afetivo também pode ficar suspenso pelo medo da perda, o que provavelmente prejudica a postura de entrega e sintonia necessárias nessa tarefa. Já o tema da matriz de apoio apresenta-se diferenciado, pois, nesses casos, as mães, apesar de precisarem de muito mais apoio do que numa situação normal, costumam, em contrapartida, isolar-se pela vergonha de não ter correspondido às expectativas externas. Por último, o tema da reorganização da identidade também deve sofrer o impacto da malformação do filho na medida em que a mãe fica muito mais abalada emocionalmente e não se sente valorizada em sua feminilidade por ter gestado um bebê "imperfeito".

Assim, considerando as inúmeras consequências da malformação, cabe aqui destacar a importância das intervençôes psicológicas que comumente se fazem necessárias para auxiliar especialmente as mães, mas também os pais, a exercerem com mais qualidade seu papel parental, contribuindo para se criar bases mais seguras para um bom desenvolvimento psíquico do bebê.

\section{INTERVENÇŌES PSICOLÓGICAS NO CONTEXTO DE MALFORMAÇÃO NO $\mathrm{BEBE}^{2}$}

As intervenções no contexto de malformação do bebê podem ser propostas desde o momento em que os casais tomam conhecimento do diagnóstico de malformação, seja na gestação, durante o parto, no pós-parto, ou nas semanas seguintes. Além de poder ajudá-los a compreender o diagnóstico, as características de determinada malformação, podem contribuir para prevenir os prováveis prejuízos psíquicos para mães e pais, para os bebês e para a relação entre eles. Assim, é importante ajudar mães e pais a reduzirem o impacto emocional do diagnóstico 
e da realidade, a identificar e compreender seus sentimentos, a acessar os recursos internos e externos disponíveis (Tradup, 1990), além de auxiliar com as dificuldades iniciais como amamentação e estabelecimento do contato e cuidados com o bebê (Johonsson \& Ringsberg, 2004). Waisbren (1980) salienta que é necessário intervir antes que os pais cheguem a um estado tal de exaustão e desilusão que possa vir a se cronificar.

Sobre as intervenções, a literatura apresenta, então, programas destinados a atender os pais na gestação, em psicoterapia individual, de apoio ou sistemática, em modelo de grupos, formados de acordo com a vivência de situações semelhantes (Atem, 2003), e até em atendimentos mistos, isto é, parte no hospital e parte na residência da gestante (Caron \& Maltz, 1994). Para o momento logo após o nascimento, são oferecidas intervenções de aconselhamento familiar (Pelchat $\&$ Lefevre, 2004; Pelchat et al., 1999), além de psicoterapia breve pais-bebê (Cramer \& Palacio-Espasa, 1993; Stern, 1997). Esta será particularmente destacada a seguir, tendo em vista que tem sido utilizada pela primeira autora do presente estudo (Gomes, 2007) para atender situações de malformação de bebês.

A psicoterapia pais-bebê (Cramer \& Palacio-Espasa, 1993) tem como principal característica estar voltada mais para a relação do que para o indivíduo. A "entidade" examinada nessas psicoterapias refere-se a um sistema complexo, no qual convergem as seguintes tramas: os funcionamentos particulares do pai e da mãe; as contribuições do bebê; o relacionamento desses sistemas em uma psicoterapia; e as contribuições do terapeuta. Esta técnica poderia, conforme os autores, trazer uma melhora significativa aos sintomas no bebê nos comportamentos interativos e nas representações acerca da parentalidade. $\mathrm{O}$ psicoterapeuta irá privilegiar a observação da natureza das solicitações recíprocas e as reações a elas através de modalidades interativas tais como: vocalizações, troca de olhares, toques e gestos. A partir dessas interações, o terapeuta poderá tecer interpretações para os pais acerca de suas defesas intrapsíquicas. Isso ocorre quando há uma coincidência entre um enunciado de uma fantasia conflitiva e a atualização da defesa relacionada a este conflito através de uma evitação, proibição, ruptura de contato, ou seja, um sintoma interativo observado, o que os autores chamaram de "sequência interativa sintomática” (SIS). Esta sequência é o equivalente interagido (e interpessoal) de um conflito intrapsíquico.

De acordo com os autores, alterações no comportamento manifesto e nas representações dos pais podem ser observadas já no decorrer da segunda ou terceira sessão. Quando isso ocorre, observa-se, ao mesmo tempo, uma alteração nos investimentos dos pais sobre o filho e, consequentemente, na interação pais-bebê. Sendo assim, o objetivo da psicoterapia não é o de alterar todo o funcionamento 
psíquico dos pais, mas apenas um setor de investimento circunscrito à relação com o bebê, o que, para os autores, justifica a brevidade desta técnica.

Ao analisar profundamente os fatores de mudança nas psicoterapias breves mãe-bebê, Cramer e Palacio-Espasa (1993) consideraram que, ao mudarem os investimentos e representações que têm do filho, os pais acabam por reduzir as projeções sobre a criança. São instituídos processos curativos em diferentes níveis: o das modificações das interações, que correspondem à redução das projeções, o das modificações das representações maternas sobre o filho, em particular pela descontaminação de elementos parasitas vindos do mundo interno e do passado da mãe, e o das modificações dos investimentos sobre o filho, sejam estes libidinais, agressivos ou narcisistas. Esse objetivo parece vir ao encontro das situaçôes de malformações no bebê, uma vez que as representações maternas sobre o filho precisam ser mais amplamente modificadas e adaptadas a uma nova realidade.

A importância da intervenção precoce para a prevenção de distúrbios psicológicos posteriores em crianças de alto risco tem sido destacada no estudo de Pinto (2000) com bebês prematuros brasileiros. Estes programas, segundo ela, devem iniciar o mais cedo possível, contar com processos de avaliação, orientação e psicoterapia para sua ação, além de enfocar o vínculo familiar, especialmente a figura materna. A autora apresenta o modelo de psicoterapia breve pais-bebê ou mãe-bebê como uma intervenção clínica bastante indicada para situações de alto risco, uma vez que objetiva reduzir as projeções e modificar as representações patológicas que os pais têm sobre as crianças, promovendo uma melhor qualidade da interação pais-bebê/mãe-bebê. Em um artigo mais recente (Pinto, 2004), salientou novamente esta indicação, acrescentando que essas famílias deveriam ser acompanhadas ao longo do primeiro ano de vida. Caron (2000) também salientou que, em casos especiais, nos quais os pais estão feridos narcisicamente ante situaçôes de difícil elaboração, o contexto da intervenção deve flexibilizar-se de acordo com a necessidade percebida pelo terapeuta e uma postura de respeito e compreensão é indispensável.

Neste sentido, os pais de bebês com malformação necessitam ser atendidos para superar o momento inicial de crise e, depois, reajustarem-se interna e externamente às necessidades impostas pela condição (Stern, 1999). O terapeuta, para este autor, precisa ajudar os pais a entrarem em contato com seu bebê, conhecendo seus limites e potenciais, além de integrar todas as informaçôes médicas envolvidas. Do contrário, esta fragmentação atinge o psiquismo deles, não permitindo um vínculo de mais qualidade com o bebê.

O terapeuta deve oscilar entre uma função de empatia e identificação, contendo as angústias e limitando a desorganização psíquica da mãe (Rajon, Rosé \& 
Abadie, 1997). Na relação mãe-bebê, a mãe funcionaria de "para-excitação" para o bebê enquanto ele não dispõe de tal capacidade psíquica. Em situações de malformação, esta função pode ficar prejudicada e o profissional poderá intervir nesta dificuldade, apoiando a mãe e sustentando uma posição parental que se tornou deficiente pelo trauma para que esta, por sua vez, possa oferecer uma mente mais livre de conflitos ao seu bebê. Assim, o terapeuta fica a serviço da mãe, mas também do bebê. Battikha (2001) salienta que, diante de um diagnóstico desta natureza, a mãe se vê invadida por muitas perguntas e incompreensões, e cabe ao terapeuta poder nomear parte destas experiências e representar, mesmo que parcialmente, o irrepresentável.

Embora a psicoterapia breve pais-bebê venha sendo utilizada largamente em vários contextos, como o da depressão materna (Clark, Tluczek \& Wenzel, 2003; Cooper, Murray, Wilson \& Romaniuk, 2003; Cramer, 1997; Cramer et al., 1990), acredita-se que ela possa também servir adequadamente para o contexto de malformação. O terapeuta, servindo de figura continente para as angústias e para a carga agressiva de mães e pais, auxiliará a abrir um espaço para rever as representações mentais maternas até então construídas.

\section{CONSIDERAÇÕES FINAIS}

A presente revisão evidencia claramente o sofrimento materno diante da malformação e do quanto este pode acionar e intensificar outras vivências de falhas e desvalia já presentes na vida da mãe. Além disso, destacou o papel fundamental das representaçôes maternas acerca do bebê e o quanto estas podem servir de limitadores ou propiciadores de desenvolvimento. Neste contexto, evidencia-se a importância de intervenções psicológicas, em especial a psicoterapia breve paisbebê, como capazes de afetar e modificar as representaçôes maternas.

Para tanto, é necessário que a malformação não seja tratada pelos profissionais da saúde com atenção somente nos seus aspectos físicos e funcionais, tendo em vista que os aspectos psicológicos também carecem de tratamento. Por outro lado, é importante que se entenda que, apesar de relevantes, as profilaxias que abrangem palestras, grupos e esclarecimentos de informações podem não ser suficientes para muitas mães e pais que passam a conviver com a malformação. Nestes casos, é preciso que sejam disponibilizados tratamentos psicoterápicos que acreditamos serem capazes de reduzir o intenso sofrimento presente no contexto de malformação, contribuindo para o relacionamento emocional mãe, pai e bebê com consequências positivas para o desenvolvimento deste. 


\section{REFERÊNCIAS}

Agazi, G., Arenaza, A., Carranza, R., Malik, A. \& Schorn, M. (2002). Lo esencial es invisible a los ojos. Entre obstáculos e instrumentos. In: Schorn, M. Discapacidad: una mirada distinta, una escucha diferente (pp. 49-57). Buenos Aires: Lugar.

Anzieu, D. (1989). O Eu-pele. São Paulo: Casa do Psicólogo.

Atem, L. (2003). Por que atender bebês e crianças pequenas em psicanálise? Pediatria Moderna, 39(6), 208-210.

Aulagnier, P. (2002). Nascimento de um corpo, origem de uma história. In: McDougall, J., Gachellin, P., Aulagnier, P., Marty, P., Loriod, J. \& Cain, J. Corpo e história (pp. 105-149). São Paulo: Casa do Psicólogo.

Battikha, E. (2001). Intervenção precoce no vínculo mãe-bebê especial em uma unidade de terapia intensiva neonatal. In: Camarotti, M. (org.). Atendimento ao bebê: uma abordagem interdisciplinar (pp. 43-48). São Paulo: Casa do Psicólogo.

Bertoldi, C. (2002). Que dor é essa? In: Bernardino, L. \& Rohenkohl, C. (org.). O bebê e a modernidade: abordagens teórico-clínicas (pp. 193-203). Casa do Psicólogo: São Paulo.

Bion, W. (1976/1992). Conversando com Bion: quatro discussões com W. R. Bion, Bion em Nova Iorque e em São Paulo. Rio de Janeiro: Imago.

Birchal, P. (2006). O bebê desnutrido e sua mãe. In: Melgaço, R. (org.). A ética na atenção ao bebê: psicanálise, saúde, educação (pp. 109-113). São Paulo: Casa do Psicólogo.

Brazelton, T. \& Cramer, B. (1992). As primeiras relaçôes. São Paulo: Martins Fontes.

Carey, L., Nicholson, B. \& Fox, R. (2002). Maternal factors related to parenting young children with congenital heart disease. Journal of Pediatric Nursing, 17(3), 175-183.

Caron, N. (2000). O ambiente intra-uterino e a relação materno-fetal. In: Caron, N. (org.). A relação pais-bebê: da observação à clínica (pp. 119-134). São Paulo: Casa do Psicólogo.

Caron, N. \& Maltz, R. (1994). Intervenção em grávidas com anomalias fetais. Revista de Psiquiatria do Rio Grande do Sul, 16(3), 202-207.

Chess, S. \& Hossibi, M. (1982). Princípios e prática da psiquiatria infantil. Porto Alegre: Artes Médicas.

Clark, R., Tluczek, A. \& Wenzel, A. (2003). Psychotherapy for postpartum depression: a preliminary report. American Journal of Orthopsychiatry, 73(4), 441-454.

Colares, V. \& Richman, L. (2002). Fatores psicológicos e sociais relacionados às crianças portadoras de fissuras labiopalatais. Pediatria Moderna, 38(11), 513-516.

Cooper, P., Murray, L., Wilson, A. \& Romaniuk, H. (2003). Controlled trial of the short and long-term effect of psychological treatment of post-partum depression - Impact on maternal mood. British Journal of Psychiatry, 182, 412-419.

Psic. Clin., Rio De Janeiro, vol.22, N.I, P.I5 - 38, 2010 
Cramer, B. G. (1997). Psychodynamic perspectives on the treatment of postpartum depression. In: Murray, L. \& Cooper, P. J. (orgs.). Postpartum depression and child development (pp.237-261). New York: The Guilford Press.

Cramer, B. \& Palacio-Espasa, F. (1993). Técnicas psicoterápicas mãelbebê. Porto Alegre: Artes Médicas.

Cramer, B., Robert-Tissot, C., Stern, D. N., Serpa-Rusconi, S., Muralt, M., Besson, G., Palacio-Espasa, F., Bachmann, J. P., Knauer, D., Berney, C. \& D'arcis, U. (1990). Outcome evaluation in brief mother-infant psychotherapy: a preliminary report. Infant Mental Health Journal, 11(3), 278-300.

Crow, G. (1996). Investigating mother-infant interaction. Heart, 76, 8-9.

Debray, R. (1988). Bebês/mães em revolta: tratamentos psicanaliticos conjuntos dos desequilíbrios psicossomáticos precoces. Porto Alegre: Artes Médicas.

De Maso, D., Campis, L., Wypij, D., Bertram, S., Lipshitz, M. \& Freed, M. (1991). The impact of maternal perceptions and medical severity on the adjustment of children with congenital heart disease. Journal of Pediatric Psychology, 16(2), 137-149.

Dias, M. (2006). Uma escuta psicanalítica em neonatologia. In: Melgaço, R. (org.). A ética na atenção ao bebê: psicanálise, saúde, educação (pp. 137-147). São Paulo: Casa do Psicólogo.

Drotar, D., Baskiewicz, A., Irvin, N., Kennel, J. \& Klaus, M. (1975). The adaptation of parents to the birth of an infant with a congenital malformation: a hypothetical model. Pediatrics, 56(5), 710-717.

Farel, A., Freeman, V., Keenan, N. \& Huber, C. (1991). Interaction between high-risk infants and their mothers: the NCAST as an assessment tool. Research in Nursing \& Health, 14, 109-118.

Freud, S. (1913/1969). Tabu e ambivalência emocional. Obras completas, ESB, v. XIII. Rio de Janeiro: Imago.

Freud, S. (1926/1969). Inibição, sintoma e ansiedade. Obras completas, ESB, v. XX. Rio de Janeiro: Imago.

Gardner, F., Freeman, N., Black, A. \& Angelini, G. (1996). Disturbed mother-infant interaction in association with congenital heart disease. Heart, 76, 56-59.

Goldberg, S., Morris, P., Simmons, R., Fowler, R. \& Levison, H. (1990). Chronic illness in infancy and parenting stress: a comparison of three groups of parents. Journal of Pediatric Psychology, 15(3), 347-358.

Gomes, A. (2007). Malformação do bebê e maternidade: impacto de uma psicoterapia breve pais-bebê para as representaçôes da mãe. Tese de doutorado não publicada. Instituto de Psicologia, Universidade Federal do Rio Grande do Sul, Rio Grande do Sul, Brasil.

Gordeuk, A. (1976). Motherhood and a less than perfect child: a literary review. Maternal Child Nursing Journal, 5(2), 57-68. 
Irvin, N., Kennel, J. \& Klaus, M. (1993). Atendimento aos pais de um bebê com malformação congênita. In: Klaus, M. \& Kennel, J. Pais/Bebê: a formação do apego (pp. 245-275). Porto Alegre: Artes Médicas.

Jerusalinsky, J. (2001). Quando o que se antecipa é o fracasso... prevenção secundária e estimulação precoce. In: Camarotti, M. (org.). Atendimento ao bebê: uma abordagem interdisciplinar (pp. 35-42). São Paulo: Casa do Psicólogo.

Jerusalinsky, J. (2002). Crônica de um bebê com morte anunciada - intervindo com a instauração do sujeito na iminência da morte. In: Bernardino, L. \& Rohenkohl, C. (org.). O bebê e a modernidade: abordagens teórico-clinicas (pp. 169-178). São Paulo: Casa do Psicólogo.

Johonsson, B. \& Ringsberg, K. (2004). Parent's experiences of having a child with cleft lip and palate. Journal of Advanced Nursing, 47(2), 165-173.

Kroeff, C., Maia, C. \& Lima, C. (2000). O luto do filho malformado. Femina, 28, 395-396. Lebovici, S. (1992). Maternidade. In: Costa, G. (org.). Dinâmica das relaçôes conjugais. Porto Alegre: Artes Médicas.

Malucelli, D. (2002). Quando a anatomia é mesmo o destino... In: Bernardino, L. \& Rohenkohl, C. (org.). O bebê e a modernidade: abordagens teórico-clinicas (pp. 161-167). Casa do Psicólogo: São Paulo.

Mannoni, M. (1999). A criança retardada e a mãe. Martins Fontes: São Paulo.

Maury, M. (1999). Intervençôes psicoterápicas nos bebês e seus pais no hospital. In: Guedeney, A. \& Lebovici, S. Intervençôes psicoterápicas pais/bebê (pp. 119-133). Porto Alegre: Artes Médicas.

Nussbaum, R., Mcinnes, R. \& Willard, H. (2002). Thompson e Thompson Genética Médica. São Paulo: Guanabara Koogan.

Pelchat, D. \& Lefevre, H. (2004). A holistic intervention programme for families with a child with a disability. Journal of Advanced Nursing, 48(2), 124-131.

Pelchat, D., Bisson, J., Ricard, N., Perreault, M. \& Bouchard, J. (1999). Longitudinal effects of an early family intervention programme on the adaptation of parents of children with a disability. International Journal of Nursing Studies, 36, 465-477.

Pinto, E. (2000). Psicoterapia breve pais-bebê/criança. In: Rohenkohl, C. (org.). A clínica com o bebê (pp. 125-130). São Paulo: Casa do Psicólogo.

Pinto, E. (2004). Os sintomas funcionais e as consultas terapêuticas pais/bebê. Estudos de Psicologia, 9(3), 451-457.

Prada, C., Valle, T. \& Pimentel, M. (2000). A percepção de si da criança portadora de fissura labiopalatal. Pediatria Moderna, 36(3), 103-107.

Quayle, J. (1997). Óbito fetal e anomalias fetais: repercussões emocionais maternas. In: Zugaib, M., Tedesco. J. \& Quayle, J. Obstetrícia psicossomática (pp. 216-227). São Paulo: Atheneu. 
Rajon, A., Rosé, D. \& Abadie, I. (1997). Observação do lactente e atendimento terapêutico do par mãe-filho, no contexto de diagnóstico perinatal de malformação. In: Lacroix, M. \& Monmayrant, M. (orgs.). A observação de bebês: os laços do encantamento (pp. 226-231). Porto Alegre: Artes Médicas.

Ramona-Thieme, M. (1995). Becoming a mother: research on maternal identity from Rubin to the present. New York: Spring Publishing.

Raphael-Leff, J. (1997). Gravidez: a história interior. Porto Alegre: Artes Médicas.

Roelofsen, E., Kamerbeek, L. \& Tymstra, T. (1993). Chances and choices. Psycho-social consequence of maternal serum screening: a report from The Netherlands. Journal of Reproductive and Infant Psychology, 11, 41-47.

Rubin, R. (1975). Maternal tasks in pregnancy. Maternal-child Nursing, 4, 143-153.

Santos, M. (2005). El lado obscuro de la maternidad - cuando nace un niño con discapacidad. In: Oiberman, A. (org.). Nacer y después... Aportes a la psicología perinatal (pp. 193-201). Buenos Aires: JCE Ediciones.

Schorn, M. (2002). Discapacidad, una mirada distinta, una escucha diferente. Buenos Aires: Lugar Editorial.

Sinason, V. (1993). Your handicapped child. Londres: Rosendale Press.

Solis-Ponton, L. (2004). Construcción de la parentalidad. In: Solis-Ponton, L. (org.). La parentalidad: desafio para el tercer milenio - un homenaje a Serge Lebovici (pp. 11-22). México: Editorial El Manual Moderno.

Speltz, M., Endriga, M., Fisher, P. \& Mason, C. (1997). Early predictor of attachment in infants with cleft lip and/or palate. Child development, 68(1), 12-25.

Stern, D. (1997). A constelação da maternidade. Porto Alegre: Artes Médicas.

Stern, D. (1999). El nacimiento de una madre: cómo la experiencia de la maternidad te cambia para siempre. Buenos Aires: Paidós.

Svavarsdottir, E. \& McCubbin, M. (1996). Parenthood transition for parents of an infant diagnosed with a congenital heart condition. Journal of Pediatric Nursing, 11(4), 207216.

Szejer, M. \& Stewart, R. (1997). Nove meses na vida da mulher. São Paulo: Casa do Psicólogo.

Tradup, J. (1990). What do I say when a baby is born with a birth defect? National Student Nursing Association, 37(4), 84-85.

Trolt, M. (1983). Birth of a sick or handicapped infant: impact on the family. Child Welfare, 62(4), 337-349.

Waisbren, S. (1980). Parent's reactions after the birth of a developmentally disabled child. American Journal of Mental Deficiency, 84(4), 345-351.

Zugaib, M. (2004). Medicina fetal. São Paulo: Atheneu. 


\section{Notas}

1 Este artigo é baseado em parte na tese de doutorado de Aline Grill Gomes, apresentada no Programa de Pós-graduação de Psicologia da Universidade Federal do Rio Grande do Sul, intitulada "Malformação do bebê e maternidade: impacto de uma psicoterapia breve paisbebê para as representações da mãe" e apresentada em agosto de 2007, sob a orientação de Cesar Augusto Piccinini e orientação clínica de Luis Carlos Prado.

2 Esta seção foi baseada no artigo "Psicoterapia breve pais-bebê: revisando a literatura", de autoria de Luiz Carlos Prado, Aline Grill Gomes, Milena da Rosa Silva, Giana Bitencourt Frizzo, Cristiane Ajnamei dos Santos Alfaya, Daniela Delias de Souza Schwengber, Rita Sobreira Lopes e Cesar Augusto Piccinini (no prelo).

Recebido em 07 de junho de 2009 Aceito para publicação em 05 de março de 2010 